\title{
Revised Korean Cough Guidelines, 2020: Recommendations and Summary Statements
}

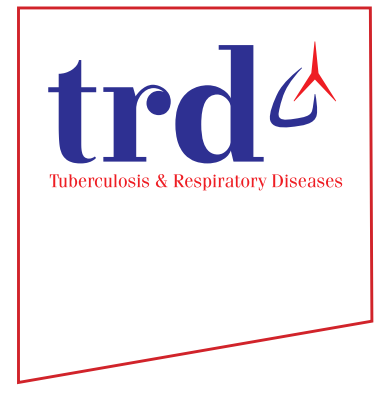

Hyonsoo Joo, M.D., Ph.D. ${ }^{1, * \mathbb{B}}$, Ji-Yong Moon, M.D., Ph.D. ${ }^{2, *(\mathbb{D})}$, Tai Joon An, M.D. ${ }^{3}$, Hayoung Choi, M.D. , So Young Park, M.D., Ph.D. ${ }^{5}$, Hongseok Yoo, M.D., Ph.D. ${ }^{6}$, Chi Young Kim, M.D. ${ }^{7}$, Ina Jeong, M.D., Ph.D. ${ }^{8}$, Joo-Hee Kim, M.D., Ph.D. ${ }^{9}$, Hyeon-Kyoung Koo, M.D., Ph.D. ${ }^{10}$, Chin Kook Rhee, M.D., Ph.D. ${ }^{11}$, Sei Won Lee, M.D., Ph.D. ${ }^{12}$, Sung Kyoung Kim, M.D., Ph.D. ${ }^{13}$, Kyung Hoon Min, M.D., Ph.D. ${ }^{14}$, Yee Hyung Kim, M.D., Ph.D. ${ }^{15}$, Seung Hun Jang, M.D., Ph.D. ${ }^{9}$, Deog Kyeom Kim, M.D., Ph.D. ${ }^{16}$, Jong Wook Shin, M.D., Ph.D. ${ }^{17}$, Hyoung Kyu Yoon, M.D., Ph.D. ${ }^{3}$, Dong-Gyu Kim, M.D., Ph.D. ${ }^{4}$, Hui Jung Kim, M.D., Ph.D. ${ }^{18}$ and Jin Woo Kim, M.D., Ph.D. ${ }^{1}{ }^{10}$

Author affiliations appear at the end of this article.

Cough is the most common respiratory symptom that can have various causes. It is a major clinical problem that can reduce a patient's quality of life. Thus, clinical guidelines for the treatment of cough were established in 2014 by the cough guideline committee under the Korean Academy of Tuberculosis and Respiratory Diseases. From October 2018 to July 2020, cough guidelines were revised by members of the committee based on the first guidelines. The purpose of these guidelines is to help clinicians efficiently diagnose and treat patients with cough. This article highlights the recommendations and summary of the revised Korean cough guidelines. It includes a revised algorithm for the evaluation of acute, subacute, and chronic cough. For a chronic cough, upper airway cough syndrome (UACS), cough variant asthma (CVA), and gastroesophageal reflux disease (GERD) should be considered in differential diagnoses. If UACS is suspected, first-generation antihistamines and nasal decongestants can be used empirically. In cases with CVA, inhaled corticosteroids are recommended to improve cough. In patients with suspected chronic cough due to symptomatic GERD, proton pump inhibitors are recommended. Chronic bronchitis, bronchiectasis, bronchiolitis, lung cancer, aspiration, intake of angiotensin-converting enzyme inhibitor, intake of dipeptidyl peptidase-4 inhibitor, habitual cough, psychogenic cough, interstitial lung disease, environmental and occupational factors, tuberculosis, obstructive sleep apnea, peritoneal dialysis, and unexplained cough can also be considered as causes of a chronic cough. Chronic cough due to laryngeal dysfunction syndrome has been newly added to the guidelines.

Keywords: Cough; Guideline; Korea

Address for correspondence: Jin Woo Kim, M.D., Ph.D.

Division of Pulmonary and Critical Care Medicine, Department of Internal Medicine, Uijeongbu St. Mary's Hospital, College of Medicine, The Catholic

University of Korea, 271 Cheonbo-ro, Uijeongbu 11765, Republic of Korea

Phone: 82-31-820-3945, Fax: 82-31-847-2719, E-mail: medkjw70@gmail.com

*Hyonsoo Joo and Ji-Yong Moon contributed equally to this work.

Received: Mar. 10, 2021, Revised: Apr. 10, 2021, Accepted: May. 3, 2021, Published online: May. 13, 2021

@(c) it is identical to the Creative Commons Attribution Non-Commercial License (http://creativecommons.org/licenses/by-nc/4.0/) 


\section{Introduction}

Cough is the most common respiratory symptom that can have various causes ${ }^{1}$. It is a major clinical problem that can reduce a patient's quality of life ${ }^{2}$. Thus, clinical guidelines for the treatment of cough were established in 2014 by the cough guideline committee under the Korean Academy of Tuberculosis and Respiratory Diseases. The first guidelines for cough proposed recommendations for objective and standardized diagnostic and treatment practices. It was based on a systematic literature review of domestic and international clinical studies on cough, with high degrees of evidence and strength of recommendation.

From October 2018 to July 2020, the cough guidelines were revised by members of the cough guideline committee. The purpose of these guidelines is to help clinicians efficiently diagnose and treat patients with a cough. The revised guidelines include epidemiological data on chronic cough in Korea provided by the cough guideline committee, the Cough Assessment Test (COAT) as a noble assessment tool for cough, contents of the revised American College of Chest Physicians and European Respiratory Society guidelines, and results of Korean studies based on the first cough guidelines. Contents of these guidelines are confined to only adult patients. The 2020 revision of the Korean cough guidelines was written in the Korean language and published in December 2020. In this article, we present a summary of the revised Korean cough guidelines, 2020 with recommendations.

\section{Definition, mechanism, and epidemiology of cough}

\section{1) Summary}

- Cough is a normal defense mechanism ${ }^{2}$. However, severe and/or prolonged cough is the most common symptom that results in visits to hospitals ${ }^{3}$.

\section{Classification of cough}

\section{1) Summary}

- Cough can be classified as acute ( $<3$ weeks), subacute ( 3 to 8 weeks), and chronic ( $>8$ weeks) according to its duration ${ }^{4}$.

- Classification of cough according to the duration can help diagnose the cause of cough ${ }^{5}$.

\section{Tools for assessment of cough}

\section{1) Recommendation}

- $\mathrm{COAT}^{6}$ is recommended to assess various effects of cough in a standardized manner (evidence, moderate; recommendation, strong).

\section{2) Summary}

- Tools to measure the severity of cough include the cough visual analogue scale ${ }^{7}$, the Leicester Cough Questionnaire ${ }^{3}$, Cough Symptom Score ${ }^{8}$, and COAT.

\section{Acute and subacute cough}

\section{1) Recommendation}

- If a patient with an acute cough has any warning signs (Table 1), chest X-rays are necessary regardless of the duration of cough.

- Empirical antibiotic therapy for cough due to an acute bronchitis can be considered only in patients with purulent sputum (evidence, low; recommendation, strong).

- In patients with acute and subacute cough, beta- 2 agonists should not be used to improve cough symptoms (evidence, low; recommendation, strong) ${ }^{9}$.

\section{2) Summary}

- Acute cough is defined as a cough lasting no more than 3 weeks. Upper respiratory infections and acute bronchitis caused by respiratory viruses are the most common causes ${ }^{10}$

Table 1. List of alarm signs

\begin{tabular}{|c|c|}
\hline Accompanying symptoms & $\begin{array}{l}\text { Hemoptysis } \\
\text { Prominent dyspnea, especially at rest or at night } \\
\text { Hoarseness } \\
\text { Vomiting } \\
\text { Trouble swallowing when eating or drinking } \\
\text { Systemic symptoms (fever, weight loss, peripheral edema with weight gain) }\end{array}$ \\
\hline Physical examination & Abnormal respiratory examinations (crackle/wheezing/stridor) \\
\hline Past history & $\begin{array}{l}\text { Deterioration of an underlying lung or cardiac disease } \\
\text { Recurrent pneumonia } \\
\text { Adults aged } 55-80 \text { years who have a } 30 \text { pack-year smoking history }\end{array}$ \\
\hline Change of pattern & Smoker $>45$ years of age with a newly developed cough, change in cough, or coexisting voice disturbance \\
\hline Duration & $\begin{array}{l}\text { Cough lasting }>2 \text { weeks (always consider the presence of tuberculosis in endemic areas or high-risk } \\
\text { populations even if chest radiographs are normal) }\end{array}$ \\
\hline
\end{tabular}


(Figure 1).

- In patients with acute cough without any warning signs (Table 1), symptomatic therapy is first administered before any investigations.

- Subacute cough is defined as a cough lasting 3 weeks to 8 weeks. History taking, physical examination, and chest radiography are recommended (Figure 2).
- Post-infectious cough is the most common cause of subacute cough. It is often associated with viral infections. Symptomatic treatment without antibiotics can improve the cough $^{11}$.

- Antibiotics therapy can be effective in treating subacute cough due to bacterial infections.

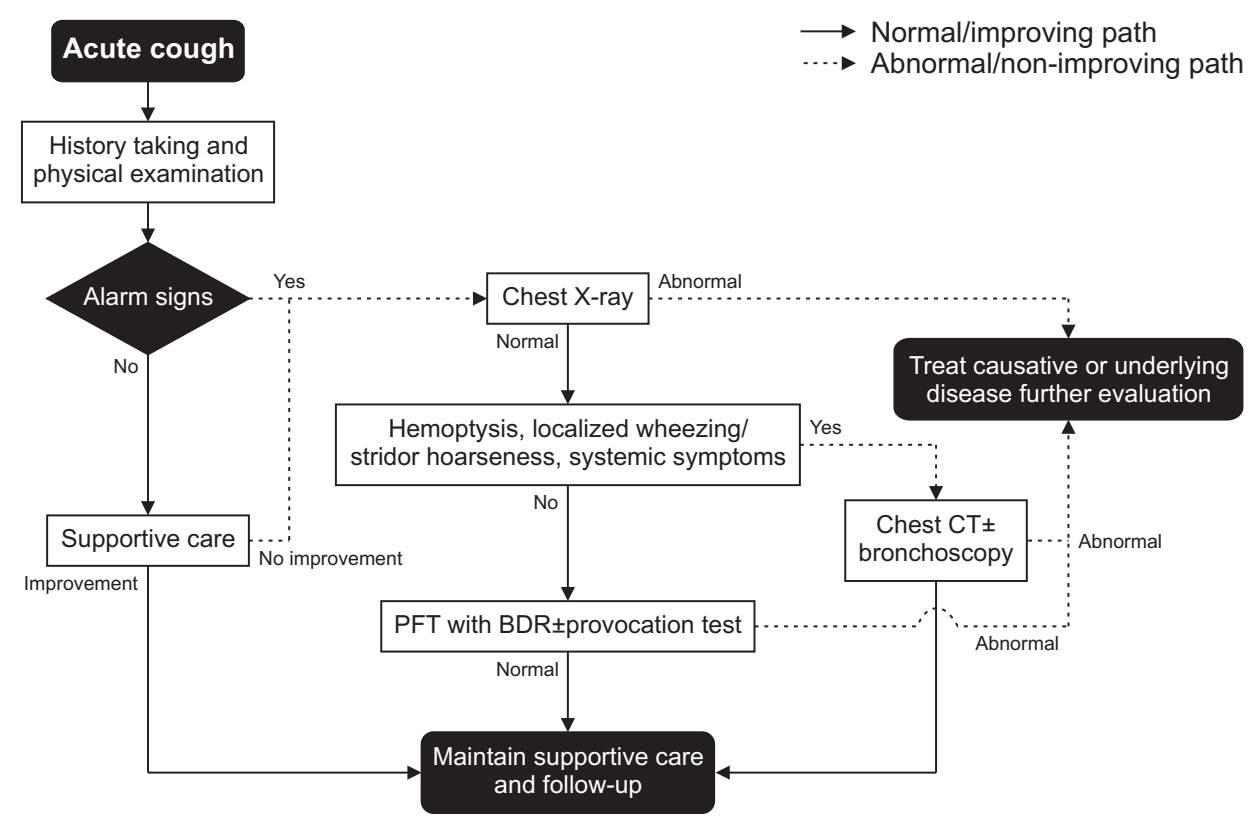

Figure 1. Algorithm for the evaluation of an acute cough. BDR: bronchodilator response; CT: computed tomography; PFT: pulmonary function test.

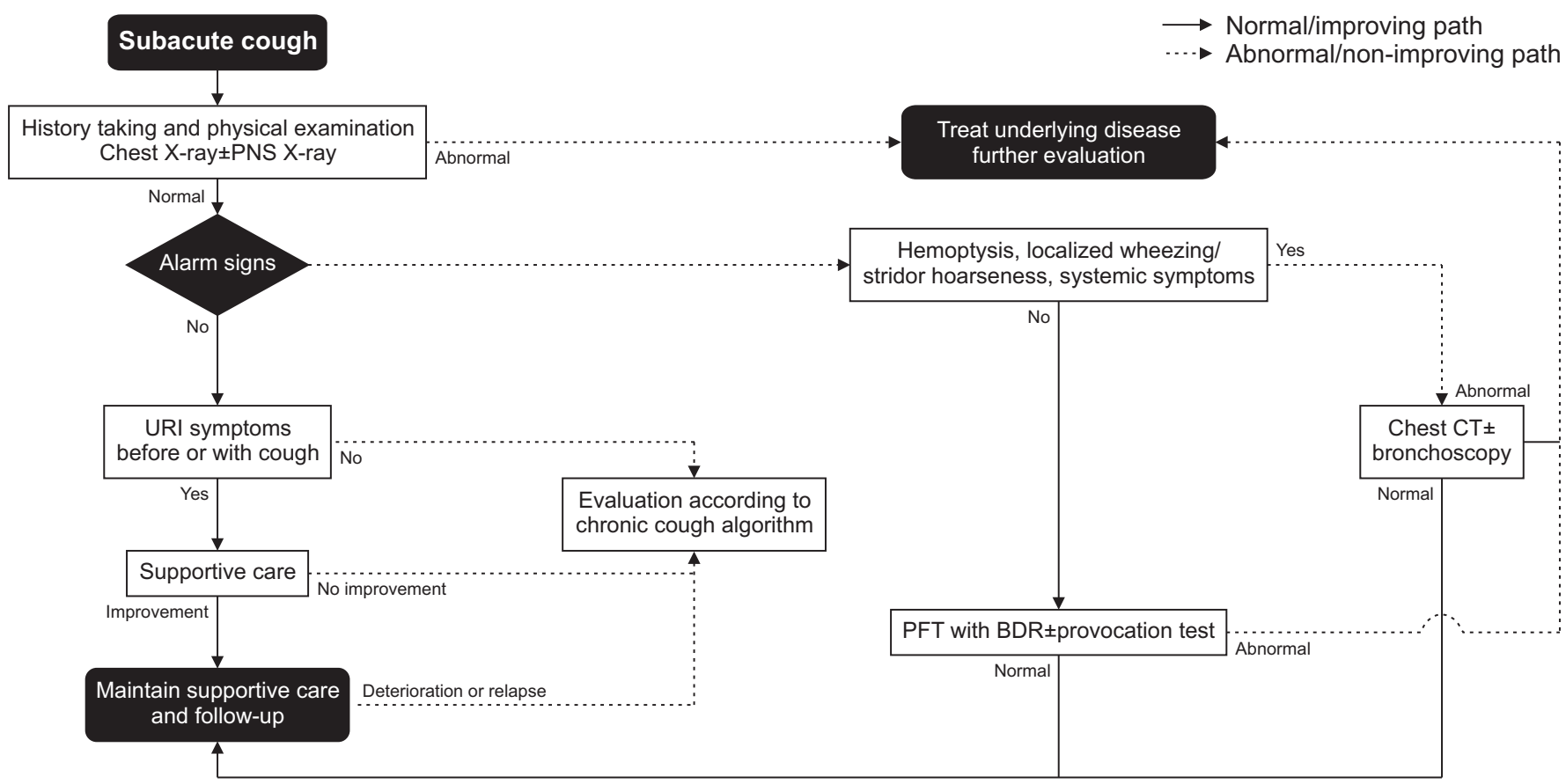

Figure 2. Algorithm for the evaluation of subacute cough. BDR: bronchodilator response; CT: computed tomography; PFT: pulmonary function test; PNS: paranasal sinus; URI: upper respiratory infection. 


\section{Chronic cough}

\section{1) Summary}

- Chronic cough is defined as a cough lasting for more than 8 weeks.

- History taking, including details of smoking habits, accompanying symptoms, and medication, is helpful for differential diagnosis. Clinicians should take it first and enough (Figure 3).

- Tests for upper airway cough syndrome (UACS), cough variant asthma (CVA), and gastroesophageal reflux disease (GERD).

- Chest radiography should be performed first ${ }^{12-15}$. Other tests can be performed in a step-wise manner based on symptoms of the patient and facilities of the hospital.

\section{Upper airway cough syndrome}

\section{1) Recommendation}

- In UACS, intranasal steroids can be used to improve cough (evidence, very low; recommendation, weak).

- In UACS, oral antihistamines are recommended to improve cough (evidence, very low; recommendation, strong).

- In UACS, only using nasal decongestant is not recommended to improve cough (evidence, expert opinion; recommendation, strong).

- In UACS, intranasal antihistamine is not considered effective in improving cough (evidence, very low; recommendation, weak).

- In UACS, antibiotics are not recommended to improve cough (evidence, expert opinion; recommendation, strong).

\section{2) Summary}

- UACS is a syndrome in which various upper airway diseases can cause a cough ${ }^{16,17}$.

- It is diagnosed based on symptoms, physical examination, radiologic findings, and response to an empirical treatment $^{18,19}$.

- If UACS is diagnosed, adequate treatment should be initi-

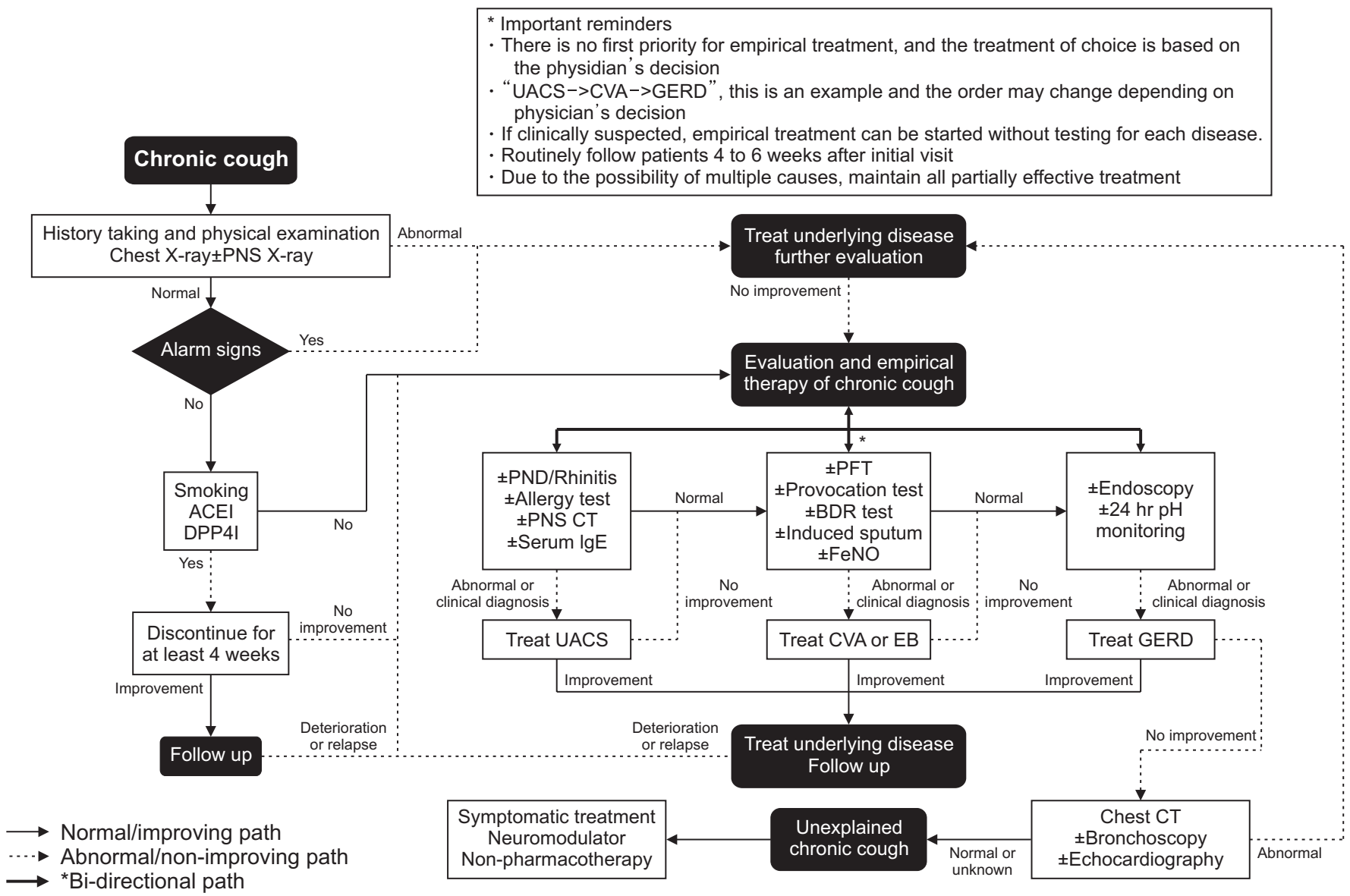

Figure 3. Algorithm for the evaluation of chronic cough. ACEI: angiotensin-converting enzyme inhibitor; BDR: bronchodilator response; CT: computed tomography; CVA: cough variant asthma; DPP4I: dipeptidylpeptidase-4 inhibitor; EB: eosinophilic bronchitis; FeNO: fractional exhaled nitric oxide; GERD: gastroesophageal reflux disease; PFT: pulmonary function test; PND: postnasal drip; PNS: paranasal sinus; UACS: upper airway cough syndrome. 
ated.

- If UACS is suspected, first-generation antihistamine and nasal decongestants can be used empirically.

\section{Cough variant asthma}

\section{1) Recommendation}

- In patients with CVA, non-invasive measurement of airway inflammation such as sputum eosinophil counts and fractional exhaled nitric oxide should be considered (evidence, moderate; recommendation, weak) ${ }^{20}$.

- In CVA, inhaled corticosteroids (ICS) are recommended to improve cough. If the cough is not well controlled with ICS, the dose of ICS may be increased and/or a leukotriene receptor antagonist (LTRA) or a long-acting bronchodilator may be added (evidence, moderate; recommendation, strong).

\section{2) Summary}

- CVA is defined as a sole symptom of cough, bronchial hyperresponsiveness, and improvement of cough after ICS treatment ${ }^{21}$.

- The key medication for CVA is ICS, which is the same as that for asthma ${ }^{20}$.

\section{Eosinophilic bronchitis (EB)}

\section{1) Recommendation}

- In EB, ICS is recommended to improve cough (evidence, expert opinion; recommendation, strong).

- In EB, LTRA is not recommended to improve cough (evidence, expert opinion; recommendation, strong).

\section{2) Summary}

- EB is defined as symptoms limited to cough without bronchial hyperresponsiveness or eosinophilic inflammation in the airway ${ }^{22,23}$.

- The key medication for EB is ICS.

\section{Gastroesophageal reflex disease}

\section{1) Recommendation}

- In patients with suspected chronic cough due to symptomatic gastroesophageal reflux, proton pump inhibitors are recommended to improve the cough (evidence, low; recommendation, weak).

\section{2) Summary}

- In patients with suspected chronic cough due to a refluxcough syndrome, we recommend the following treatment: (1) diet modification to promote weight loss in patients who are overweight or obese; (2) head of bed elevation ${ }^{24}$ and avoiding meals within 3 hours of bedtime ${ }^{25}$.

- In patients who report heartburn and regurgitation, pro- ton pump inhibitors (PPIs), H2-receptor antagonists, alginate, and antacid therapy are sufficient to control these symptoms.

- In patients with suspected chronic cough due to refluxcough syndrome without heartburn or regurgitation, using PPI therapy alone is not recommended ${ }^{26,27}$.

\section{Chronic bronchitis}

\section{1) Recommendation}

- Smoking cessation is recommended to improve cough in patients with chronic bronchitis (CB) (evidence, expert opinion; recommendation, strong).

- In CB, mucoactive agents can be considered to improve the cough (evidence, expert opinion; recommendation, weak).

\section{2) Summary}

- Treatment for CB with decreased lung function should follow chronic obstructive pulmonary disease guidelines.

- Smoking cessation is the most effective treatment for $\mathrm{CB}$ with a decreased lung function ${ }^{28,29}$.

$-\mathrm{CB}$ is the most common cause of cough in smokers ${ }^{30}$.

- Mucoactive agents are effective in improving cough in CB with a decreased lung function ${ }^{31}$.

- Inhaled short-acting beta-agonist (SABA), theophylline, ICS/long-acting beta-agonist, and codeine can be used to treat cough in CB with a decreased lung function ${ }^{32}$.

\section{Bronchiectasis}

\section{1) Summary}

- When bronchiectasis is suspected, high-resolution computed tomography (HRCT) is necessary even if chest X-ray is normal $^{33}$.

- Long-term antibiotic treatment should be cautiously considered because it can control acute exacerbation caused by infection. However, it can also lead to adverse effects ${ }^{33-37}$.

\section{Bronchiolitis}

\section{1) Recommendation}

- In diffuse panbronchiolitis, low-dose macrolide antibiotics are recommended to improve cough (evidence, expert opinion; recommendation, strong).

\section{2) Summary}

- Bronchiolitis should be preferentially considered when there are irreversible airflow obstruction, suspicion of small airway disease on HRCT, and purulent sputa in patients with a chronic cough $^{38}$. 


\section{Lung cancer}

\section{1) Summary}

- Chest X-ray should be performed in patients who have risk factors for lung cancer or metastatic lung cancer ${ }^{39}$.

- Bronchoscopy and chest CT should be performed when endobronchial invasion by the tumor is suspected even if chest X-ray is normal ${ }^{39}$.

- In patients with lung cancer, the reason for cough might not be cancer. Thus, further evaluation is necessary ${ }^{40}$.

- In patients with lung cancer, cough should be actively managed because it can affect their quality of life and progno$\operatorname{sis}^{41}$.

- In patients with lung cancer, stepwise treatment based on the mechanism of the drug should be considered to control their $\operatorname{cough}^{42}$.

\section{Aspiration}

\section{1) Summary}

- Oropharyngeal dysphagia and aspiration should be checked in cases of cough during eating or swallowing food ${ }^{43}$.

\section{Drug-induced cough}

\section{1) Recommendation}

- Angiotensin-converting enzyme inhibitors (ACEI) and dipeptidylpeptidase-4 inhibitors (DPP4I) should be considered as causes of chronic cough. Cessation of these drugs is recommended to control the cough (evidence, expert opinion; recommendation, strong).

\section{2) Summary}

- The mechanism of drug-induced cough is the accumulation of bradykinin in the upper respiratory tract ${ }^{44,45}$. ACEI and DPP4I are representative drugs that can cause a chronic cough.

- To diagnose cough due to drugs, a detailed history taking including ACEI or DPP4I intake is necessary.

- Usually, the cough subsides 1-4 weeks after cessation of these drugs. However, it can last for more than 3 months in some patients ${ }^{46-49}$.

\section{Habitual and psychogenic cough}

\section{1) Summary}

- Habitual and psychogenic cough is an unconsciously persistent cough without an underlying disease. It can be considered when there is no obvious reason for the cough, or when cough does not respond to a conventional therapy ${ }^{50,51}$.

- Habitual and psychogenic cough usually develops during childhood and adolescence. When it develops in adults, it might be accompanied by psychological conditions ${ }^{52}$.
- Habitual and psychogenic cough is characterized by aggravation during emotional stress, social activity, and disappearance during sleep. However, the presence or absence of these characteristics should not be used to diagnose or exclude a psychogenic cough ${ }^{53-55}$.

- Habitual and psychogenic cough can be diagnosed only when other causes are ruled out ${ }^{52}$.

- Psychological consultation and therapy can be consid$\operatorname{ered}^{54,56}$

\section{Interstitial lung disease}

\section{1) Recommendation}

- For patients with interstitial lung disease (ILD) who present with a troublesome cough, patients should be assessed for progression of their underlying ILD or complications from immunosuppressive treatment (e.g., adverse effects of drugs, pulmonary infection). They should also be considered for further investigation/treatment trials for their cough according to guidelines for acute, subacute, and chronic cough ${ }^{57}$.

- If alternative treatments have failed in a patient with a chronic cough due to ILD and the cough adversely affects the patient's quality of life, opiates can be used for symptom control in a palliative care setting with reassessment of the benefits and risks after one week and then monthly before continuing ${ }^{57}$.

\section{2) Summary}

- Chronic cough is a common symptom of ILD $^{57}$.

- ILD should be included in the differential diagnosis of a chronic cough since chest X-ray can be normal in 5\%-10\% of patients with early ILD.

- Progression of cough can vary according to the cause and underlying disease.

\section{Cough due to environmental and occupational factors}

\section{1) Recommendation}

- For every adult patient with a chronic cough, occupational and environmental causes should be routinely elicited in history taking.

- For a patient with a chronic cough, if the history suggests an occupational or environmental association, it be confirmed by objective testing if possible ${ }^{58}$.

\section{2) Summary}

- For an adult patient with a chronic cough and an occupational or environmental exposure history, appropriate objective tests should be performed to elucidate potential mechanistic associations between cough and the suspected exposure $^{58}$, including the following:

- Methacholine challenge for cough associated with work- 
related asthma/eosinophilic bronchitis

- Sputum/induced sputum cytology for eosinophilia

- Before and after exposure tests to demonstrate the potential causality (e.g., perform both at the end of a regular working week and, if positive, repeat at the end of a period off work such as the end of vacation, to document any work-related changes).

- Immunologic tests for hypersensitivity guided by the specific exposure history including:

o Skin tests

o Specific serum IgE antibodies

o Specific serum IgG antibodies for suspected hypersensitivity pneumonitis

o Beryllium lymphocyte proliferation tests for chronic beryllium disease

- Environmental and occupational factors can evoke cough in themselves or can aggravate cough due to other causes. Thus, consideration of environmental and occupational factors is mandatory ${ }^{58}$.

- Detailed history taking of exposure and occupation is important to identify environmental and occupational factors ${ }^{58}$.

\section{Cough due to tuberculosis and other infections}

\section{1) Recommendation}

- Considering the prevalence of tuberculosis (TB) in Korea, active TB should be suspected and evaluated for cough lasting for more than 2 weeks.

\section{2) Summary}

- Considering the prevalence of TB in Korea, active TB should be suspected in cough lasting more than 2 weeks ${ }^{59}$.

- The prevalence of nontuberculosis mycobacteria (NTM) infection in Korea continues to increase. Thus, cough due to NTM infection should be considered ${ }^{60-62}$.

\section{Obstructive sleep apnea}

\section{1) Summary}

- For an unexplained or unresponsive chronic cough, obstructive sleep apnea should be included in the differential $\operatorname{diagnosis}^{63,64}$.

\section{Cough and peritoneal dialysis}

\section{1) Summary}

- Cough is a common symptom in patients with peritoneal dialysis $^{65-67}$. Causes of cough might be GERD, ACEI, infection, pulmonary edema, and leakage of dialysis fluid ${ }^{66,68}$.

\section{Cough in immunocompromised patients}

\section{1) Summary}

- Causes of cough in immunocompromised patients are similar to those in immunocompetent patients ${ }^{69}$.

- Opportunistic infection should be included in the differential diagnosis ${ }^{70}$.

\section{Uncommon causes of cough}

\section{1) Recommendation}

- In patients with chronic cough, uncommon causes should be considered when cough persists after evaluating common causes and when the diagnostic evaluation suggests that an uncommon cause, pulmonary or extrapulmonary, is the contributing factor ${ }^{71}$.

\section{2) Summary}

- In the diagnosis of uncommon causes of cough, knowledge of the disease, clinical suspicion, and adequate evaluation are very important ${ }^{72}$.

- If cough persists after ruling out the most common causes, a CT scan should be performed. If necessary, a bronchoscopic evaluation should be perfomed ${ }^{71}$.

- In patients who present with an abrupt onset of cough, the possibility of a foreign body in the airway should be considered.

\section{Idiopathic cough (unexplained chronic cough)}

\section{1) Recommendation}

- In an idiopathic cough, an antitussive can be considered to improve the cough (evidence, expert opinion; recommendation, weak) ${ }^{73}$.

\section{2) Summary}

- A diagnosis of idiopathic cough should be made when the cough is not improved by adequate therapy and when other causes are ruled out ${ }^{15,73}$.

\section{Laryngeal dysfunction syndrome}

\section{1) Recommendation}

- In patients with a laryngeal dysfunction syndrome, multicomponent speech therapy is recommended to improve the cough.

- In patients with a laryngeal dysfunction syndrome, gabapentin, oral morphine, pregabalin, or amitriptyline is recommended to improve the cough.

- In patients with laryngeal dysfunction syndrome, local injection of botulinum toxin is recommended to improve the cough. 


\section{2) Summary}

- Laryngeal dysfunction syndrome is a cough caused by innocuous or mildly unpleasant stimuli due to laryngeal hypersensitivity and laryngeal dysfunction. It is considered as one of the causes of a chronic refractory $\operatorname{cough}^{74-76}$.

- Laryngeal dysfunction syndrome is diagnosed based on clinical features and laryngoscopic findings ${ }^{77}$.

- Speech therapy has long been considered as the mainstay of treatment for laryngeal dysfunction syndrome.

- Pharmacotherapy and local injection of botulinum toxin can be considered to improve the $\operatorname{cough}^{78}$.

26. Treatment agents for cough: antitussive and mucoactive agent

\section{1) Summary}

- Antitussives are classified as central and peripheral ${ }^{79,80}$.

- Narcotic central antitussive: morphine, codeine

- Nonopioid central antitussive: dextromethorphan, levopropoxyphene

- Peripheral antitussive: benzonatate, benproperine, theobromine

- Mucoactive agents can be classified as expectorants, mucoregulatory agents, mucolytics, and mucokinetics ${ }^{81,82}$.

- Expectorants: hypertonic saline, iodinated glycerol, domiodol, guaifenesin, and ion channel modifiers

- Mucoregulatory agents: carbocysteine, anticholinergics, glucocorticoids, and macrolide antibiotics

- Mucolytics

o Classic mucolytics: N-acetylcysteine, N-acetylin, bromhexine, erdosteine, and fudosteine

o Peptide mucolytics: dornase alpha, gelsolin, and thymo$\sin \beta 4$

○ Nondestructive mucolytics: dextran and heparin

- Mucokinetics: inhaled SABA, methylxanthine, surfactant, ambroxol, and acebrophylline

- Newly evaluated drugs include gabapentin, pregabalin, amitriptyline, and gefapixant (P2X3 receptor antagonist).

\section{Author Affiliations}

${ }^{\mathrm{l}}$ Division of Pulmonary and Critical Care Medicine, Department of Internal Medicine, Uijeongbu St. Mary's Hospital, College of Medicine, The Catholic University of Korea, Seoul, ${ }^{2}$ Department of Internal Medicine, Hanyang University Guri Hospital, Hanyang University College of Medicine, Seoul, ${ }^{3} \mathrm{Di}-$ vision of Pulmonary and Critical Care Medicine, Department of Internal Medicine, Yeouido St. Mary's Hospital, College of Medicine, The Catholic University of Korea, Seoul, ${ }^{4}$ Division of Pulmonary, Allergy and Critical Care Medicine, Hallym University Kangnam Sacred Heart Hospital, Hallym University College of Medicine, Seoul, ${ }^{5}$ Division of Pulmonary and
Critical Care Medicine, Department of Internal Medicine, College of Medicine, Ewha Womans University, Seoul, ${ }^{6}$ Division of Pulmonary and Critical Care Medicine, Department of Medicine, Lung and Esophageal Cancer Center, Sungkyunkwan University School of Medicine, Samsung Medical Center, Seoul, ${ }^{7}$ Division of Pulmonary, Allergy, and Critical Care Medicine, Department of Internal Medicine, Korea University Ansan Hospital, Ansan, ${ }^{8}$ Department of Internal Medicine, National Medical Center, Seoul, ${ }^{9}$ Division of Pulmonary, Allergy, and Critical Care Medicine, Department of Internal Medicine, Hallym University Sacred Heart Hospital, Hallym University College of Medicine, Anyang, ${ }^{10}$ Divison of Pulmonary and Critical Care Medicine, Department of Internal Medicine, Inje University Ilsan Paik Hospital, Inje University College of Medicine, Goyang, ${ }^{11}$ Division of Pulmonary and Critical Care Medicine, Department of Internal Medicine, Seoul St. Mary's Hospital, College of Medicine, The Catholic University of Korea, Seoul, ${ }^{12}$ Department of Pulmonology and Critical Care Medicine, Asan Medical Center, University of Ulsan College of Medicine, Seoul, ${ }^{13}$ Division of Pulmonary and Critical Care Medicine, Department of Internal Medicine, St. Vincent's Hospital, College of Medicine, The Catholic University of Korea, Suwon, ${ }^{14}$ Division of Pulmonary, Allergy, and Critical Care Medicine, Department of Internal Medicine, Korea University Guro Hospital, Korea University College of Medicine, Seoul, ${ }^{15}$ Department of Pulmonary, Allergy, and Critical Care Medicine, Kyung Hee University Hospital at Gangdong, Kyung Hee University School of Medicine, Seoul, ${ }^{16}$ Division of Pulmonary and Critical Care Medicine, Department of Internal Medicine, Seoul Metropolitan Government-Seoul National University Boramae Medical Center, Seoul National University College of Medicine, Seoul, ${ }^{17}$ Division of Pulmonary, Allergy, and Critical Care Medicine, Department of Internal Medicine, ChungAng University College of Medicine, Seoul, ${ }^{18}$ Division of Pulmonary and Critical Care Medicine, Department of Internal Medicine, Wonkwang University Sanbon Hospital, Wonkwang University School of Medicine, Gunpo, Republic of Korea

\section{Authors' Contributions}

Conceptualization: Kim JW, Kim DG, Kim HJ. Methodology: Kim DK, Shin JW, Yoon HK, Jang SH. Formal analysis: Min KH, Kim YH, Kim SK. Data curation: Jeong I, Kim JH, Lee SW. Software: Joo H. Validation: Kim CY, Park SY. Investigation: Choi H, Yoo H. Writing - original draft preparation: Joo H. Writing - review and editing: Koo HK, Moon JY, An TJ, Rhee CK. Approval of final manuscript: all authors.

\section{Conflicts of Interest}

No potential conflict of interest relevant to this article was 
reported.

\section{Funding}

No funding to declare.

\section{References}

1. Irwin RS, French CT, Lewis SZ, Diekemper RL, Gold PM; CHEST Expert Cough Panel. Overview of the management of cough: CHEST Guideline and Expert Panel Report. Chest 2014;146:885-9.

2. Irwin RS. Complications of cough: ACCP evidence-based clinical practice guidelines. Chest 2006;129(1 Suppl):54S-8S.

3. Birring SS, Prudon B, Carr AJ, Singh SJ, Morgan MD, Pavord ID. Development of a symptom specific health status measure for patients with chronic cough: Leicester Cough Questionnaire (LCQ). Thorax 2003;58:339-43.

4. Pratter MR, Brightling CE, Boulet LP, Irwin RS. An empiric integrative approach to the management of cough: ACCP evidence-based clinical practice guidelines. Chest 2006;129(1 Suppl):222S-31S.

5. Irwin RS, French CL, Chang AB, Altman KW; CHEST Expert Cough Panel. Classification of cough as a symptom in adults and management algorithms: CHEST Guideline and Expert Panel report. Chest 2018;153:196-209.

6. Koo HK, Jeong I, Kim JH, Kim SK, Shin JW, Park SY, et al. Development and validation of the COugh Assessment Test (COAT). Respirology 2019;24:551-7.

7. Lee KK, Matos S, Evans DH, White P, Pavord ID, Birring SS. A longitudinal assessment of acute cough. Am J Respir Crit Care Med 2013;187:991-7.

8. Hsu JY, Stone RA, Logan-Sinclair RB, Worsdell M, Busst CM, Chung KF. Coughing frequency in patients with persistent cough: assessment using a 24 hour ambulatory recorder. Eur Respir J 1994;7:1246-53.

9. Becker LA, Hom J, Villasis-Keever M, van der Wouden JC. Beta2-agonists for acute cough or a clinical diagnosis of acute bronchitis. Cochrane Database Syst Rev 2015;2015: CD001726.

10. Armstrong GL, Pinner RW. Outpatient visits for infectious diseases in the United States, 1980 through 1996. Arch Intern Med 1999;159:2531-6.

11. Braman SS. Postinfectious cough: ACCP evidence-based clinical practice guidelines. Chest 2006;129(1 Suppl):138S46S.

12. Asthma Workgroup, Chinese Society, Respiratory, Diseases (CSRD), Chinese Medical, Association. The Chinese national guidelines on diagnosis and management of cough (December 2010). Chin Med J (Engl) 2011;124:3207-19.

13. Committee for the Japanese Respiratory Society Guidelines for Management of Cough; Kohno S, Ishida T, Uchida Y, Kishimoto H, Sasaki H, et al. The Japanese Respiratory Society guidelines for management of cough. Respirology 2006;11 Suppl 4:S135-86.

14. McGarvey LP. Cough 6: Which investigations are most useful in the diagnosis of chronic cough? Thorax 2004;59:342-6.

15. Morice AH, McGarvey L, Pavord I; British Thoracic Society Cough Guideline Group. Recommendations for the management of cough in adults. Thorax 2006;61 Suppl 1:i1-24.

16. Pratter MR, Bartter T, Akers S, DuBois J. An algorithmic approach to chronic cough. Ann Intern Med 1993;119:977-83.

17. Irwin RS, Curley FJ, French CL. Chronic cough. The spectrum and frequency of causes, key components of the diagnostic evaluation, and outcome of specific therapy. Am Rev Respir Dis 1990;141:640-7.

18. Morice AH. Post-nasal drip syndrome: a symptom to be sniffed at? Pulm Pharmacol Ther 2004;17:343-5.

19. Pratter MR, Bartter T, Lotano R. The role of sinus imaging in the treatment of chronic cough in adults. Chest 1999;116:1287-91.

20. Cote A, Russell RJ, Boulet LP, Gibson PG, Lai K, Irwin RS, et al. Managing chronic cough due to asthma and NAEB in adults and adolescents: CHEST Guideline and Expert Panel report. Chest 2020;158:68-96.

21. Bateman ED, Hurd SS, Barnes PJ, Bousquet J, Drazen JM, FitzGerald JM, et al. Global strategy for asthma management and prevention: GINA executive summary. Eur Respir J 2008;31:143-78.

22. Gibson PG, Dolovich J, Denburg J, Ramsdale EH, Hargreave FE. Chronic cough: eosinophilic bronchitis without asthma. Lancet 1989;1:1346-8.

23. Brightling CE, Ward R, Goh KL, Wardlaw AJ, Pavord ID. Eosinophilic bronchitis is an important cause of chronic cough. Am J Respir Crit Care Med 1999;160:406-10.

24. Khan BA, Sodhi JS, Zargar SA, Javid G, Yattoo GN, Shah A, et al. Effect of bed head elevation during sleep in symptomatic patients of nocturnal gastroesophageal reflux. J Gastroenterol Hepatol 2012;27:1078-82.

25. Kahrilas PJ, Altman KW, Chang AB, Field SK, Harding SM, Lane AP, et al. Chronic cough due to gastroesophageal reflux in adults: CHEST Guideline and Expert Panel report. Chest 2016;150:1341-60.

26. Chang AB, Lasserson TJ, Kiljander TO, Connor FL, Gaffney JT, Garske LA. Systematic review and meta-analysis of randomised controlled trials of gastro-oesophageal reflux interventions for chronic cough associated with gastro-oesophageal reflux. BMJ 2006;332:11-7.

27. Chang AB, Lasserson TJ, Gaffney J, Connor FL, Garske LA. Gastro-oesophageal reflux treatment for prolonged nonspecific cough in children and adults. Cochrane Database Syst Rev 2011;2011:CD004823.

28. Kanner RE, Connett JE, Williams DE, Buist AS. Effects of randomized assignment to a smoking cessation intervention 
and changes in smoking habits on respiratory symptoms in smokers with early chronic obstructive pulmonary disease: the Lung Health Study. Am J Med 1999;106:410-6.

29. Wynder EL, Kaufman PL, Lesser RL. A short-term follow-up study on ex-cigarette smokers: with special emphasis on persistent cough and weight gain. Am Rev Respir Dis 1967;96: 645-55.

30. Malesker MA, Callahan-Lyon P, Madison JM, Ireland B, Irwin RS; CHEST Expert Cough Panel. Chronic cough due to stable chronic bronchitis: CHEST Expert Panel report. Chest 2020;158:705-18.

31. Cazzola M, Floriani I, Page CP. The therapeutic efficacy of erdosteine in the treatment of chronic obstructive bronchitis: a meta-analysis of individual patient data. Pulm Pharmacol Ther 2010;23:135-44.

32. Calverley P, Pauwels R, Vestbo J, Jones P, Pride N, Gulsvik A, et al. Combined salmeterol and fluticasone in the treatment of chronic obstructive pulmonary disease: a randomised controlled trial. Lancet 2003;361:449-56.

33. McGuinness G, Naidich DP. CT of airways disease and bronchiectasis. Radiol Clin North Am 2002;40:1-19.

34. Serisier DJ, Martin ML, McGuckin MA, Lourie R, Chen AC, Brain B, et al. Effect of long-term, low-dose erythromycin on pulmonary exacerbations among patients with non-cystic fibrosis bronchiectasis: the BLESS randomized controlled trial. JAMA 2013;309:1260-7.

35. Altenburg J, de Graaff CS, Stienstra Y, Sloos JH, van Haren EH, Koppers RJ, et al. Effect of azithromycin maintenance treatment on infectious exacerbations among patients with noncystic fibrosis bronchiectasis: the BAT randomized controlled trial. JAMA 2013;309:1251-9.

36. Wong C, Jayaram L, Karalus N, Eaton T, Tong C, Hockey H, et al. Azithromycin for prevention of exacerbations in noncystic fibrosis bronchiectasis (EMBRACE): a randomised, double-blind, placebo-controlled trial. Lancet 2012;380:6607 .

37. Evans DJ, Bara AI, Greenstone M. Prolonged antibiotics for purulent bronchiectasis in children and adults. Cochrane Database Syst Rev 2007;(2):CD001392.

38. Brown KK. Chronic cough due to nonbronchiectatic suppurative airway disease (bronchiolitis): ACCP evidence-based clinical practice guidelines. Chest 2006;129(1 Suppl):132S-7S.

39. Shure D. Radiographically occult endobronchial obstruction in bronchogenic carcinoma. Am J Med 1991;91:19-22.

40. Molassiotis A, Smith JA, Mazzone P, Blackhall F, Irwin RS; CHEST Expert Cough Panel. Symptomatic treatment of cough among adult patients with lung cancer: CHEST Guideline and Expert Panel report. Chest 2017;151:861-74.

41. Temel JS, Greer JA, Muzikansky A, Gallagher ER, Admane S, Jackson VA, et al. Early palliative care for patients with metastatic non-small-cell lung cancer. N Engl J Med 2010;363:73342.

42. Molassiotis A, Smith JA, Bennett MI, Blackhall F, Taylor D,
Zavery B, et al. Clinical expert guidelines for the management of cough in lung cancer: report of a UK task group on cough. Cough 2010;6:9.

43. Robbins J, Coyle J, Rosenbek J, Roecker E, Wood J. Differentiation of normal and abnormal airway protection during swallowing using the penetration-aspiration scale. Dysphagia 1999;14:228-32.

44. Grouzmann E, Monod M, Landis B, Wilk S, Brakch N, Nicoucar K, et al. Loss of dipeptidylpeptidase IV activity in chronic rhinosinusitis contributes to the neurogenic inflammation induced by substance P in the nasal mucosa. FASEB J 2002;16: 1132-4.

45. Landis BN, Grouzmann E, Monod M, Busso N, Petak F, Spiliopoulos A, et al. Implication of dipeptidylpeptidase IV activity in human bronchial inflammation and in bronchoconstriction evaluated in anesthetized rabbits. Respiration 2008;75:89-97.

46. Israili ZH, Hall WD. Cough and angioneurotic edema associated with angiotensin-converting enzyme inhibitor therapy: a review of the literature and pathophysiology. Ann Intern Med 1992;117:234-42.

47. Lacourciere Y, Brunner H, Irwin R, Karlberg BE, Ramsay LE, Snavely DB, et al. Effects of modulators of the renin-angiotensin-aldosterone system on cough. Losartan Cough Study Group. J Hypertens 1994;12:1387-93.

48. Dicpinigaitis PV. Angiotensin-converting enzyme inhibitorinduced cough: ACCP evidence-based clinical practice guidelines. Chest 2006;129(1 Suppl):169S-73S.

49. Baraniuk JN, Jamieson MJ. Rhinorrhea, cough and fatigue in patients taking sitagliptin. Allergy Asthma Clin Immunol 2010;6:8.

50. Bryon M, Jaffe A. Disabling cough: habit disorder or tic syndrome? Lancet 2003;361:1991-2.

51. Weinberger M. Disabling cough: habit disorder or tic syndrome? Lancet 2003;361:1991.

52 . Weinberger M. The habit cough syndrome and its variations. Lung 2012;190:45-53.

53. Kravitz H, Gomberg RM, Burnstine RC, Hagler S, Korach A. Psychogenic cough tic in children and adolescents. Nine case histories illustrate the need for re-evaluation of this common but frequently unrecognized problem. Clin Pediatr (Phila) 1969;8:580-3.

54. Gay M, Blager F, Bartsch K, Emery CF, Rosenstiel-Gross AK, Spears J. Psychogenic habit cough: review and case reports. J Clin Psychiatry 1987;48:483-6.

55. Blager FB, Gay ML, Wood RP. Voice therapy techniques adapted to treatment of habit cough: a pilot study. J Commun Disord 1988;21:393-400.

56. Cohlan SQ, Stone SM. The cough and the bedsheet. Pediatrics 1984;74:11-5.

57. Birring SS, Kavanagh JE, Irwin RS, Keogh KA, Lim KG, Ryu JH, et al. Treatment of interstitial lung disease associated cough: CHEST Guideline and Expert Panel report. Chest 2018;154: 
904-17.

58. Tarlo SM, Altman KW, Oppenheimer J, Lim K, Vertigan A, Prezant D, et al. Occupational and environmental contributions to chronic cough in adults: Chest Expert Panel report. Chest 2016;150:894-907.

59. Joint Committee for the Revision of Korean Guidelines for Tuberculosis Korea Centers for Disease Control and Prevention. Korean guidelines for tuberculosis. 4th ed. Seoul: Joint Committee for the Revision of Korean Guidelines for Tuberculosis, Korea Centers for Disease Control and Prevention; 2020.

60. Kim N, Yi J, Chang CL. Recovery rates of non-tuberculous mycobacteria from clinical specimens are increasing in Korean tertiary-care hospitals. J Korean Med Sci 2017;32:1263-7.

61. Ko RE, Moon SM, Ahn S, Jhun BW, Jeon K, Kwon OJ, et al. Changing epidemiology of nontuberculous mycobacterial lung diseases in a tertiary referral hospital in Korea between 2001 and 2015. J Korean Med Sci 2018;33:e65.

62. Lee H, Myung W, Koh WJ, Moon SM, Jhun BW. Epidemiology of nontuberculous mycobacterial infection, South Korea, 2007-2016. Emerg Infect Dis 2019;25:569-72.

63. Sundar KM, Daly SE, Pearce MJ, Alward WT. Chronic cough and obstructive sleep apnea in a community-based pulmonary practice. Cough 2010;6:2.

64. Birring SS, Ing AJ, Chan K, Cossa G, Matos S, Morgan MD, et al. Obstructive sleep apnoea: a cause of chronic cough. Cough 2007;3:7.

65. Holley JL, Piraino B. CAPD-associated cough. Perit Dial Int 1995; 15:392-3.

66. Min F, Tarlo SM, Bargman J, Poonai N, Richardson R, Oreopoulos D. Prevalence and causes of cough in chronic dialysis patients: a comparison between hemodialysis and peritoneal dialysis patients. Adv Perit Dial 2000;16:129-33.

67. Tarlo SM. Peritoneal dialysis and cough. Perit Dial Int 2003;23:424-6.

68. Twardowski ZJ, Khanna R, Nolph KD, Scalamogna A, Metzler $\mathrm{MH}$, Schneider TW, et al. Intraabdominal pressures during natural activities in patients treated with continuous ambulatory peritoneal dialysis. Nephron 1986;44:129-35.

69. Rosen MJ, Ireland B, Narasimhan M, French C, Irwin RS; CHEST Expert Cough Panel. Cough in ambulatory immu- nocompromised adults: CHEST Expert Panel report. Chest 2017;152:1038-42.

70. Maschmeyer G, Beinert T, Buchheidt D, Einsele H, Heussel CP, Kiehl M, et al. Diagnosis and antimicrobial therapy of pulmonary infiltrates in febrile neutropenic patients: guidelines of the Infectious Diseases Working Party (AGIHO) of the German Society of Hematology and Oncology (DGHO). Ann Hematol 2003;82 Suppl 2:S118-26.

71. Prakash UB. Uncommon causes of cough: ACCP evidencebased clinical practice guidelines. Chest 2006;129(1 Suppl):206S-19S.

72. McGarvey LP, Heaney LG, Lawson JT, Johnston BT, Scally $\mathrm{CM}$, Ennis M, et al. Evaluation and outcome of patients with chronic non-productive cough using a comprehensive diagnostic protocol. Thorax 1998;53:738-43.

73. Pratter MR. Unexplained (idiopathic) cough: ACCP evidence-based clinical practice guidelines. Chest 2006;129(1 Suppl):220S-1S.

74. Hull JH, Menon A. Laryngeal hypersensitivity in chronic cough. Pulm Pharmacol Ther 2015;35:111-6.

75. Vertigan AE, Bone SL, Gibson PG. Laryngeal sensory dysfunction in laryngeal hypersensitivity syndrome. Respirology 2013;18:948-56.

76. Vertigan AE, Gibson PG, Theodoros DG, Winkworth AL. A review of voice and upper airway function in chronic cough and paradoxical vocal cord movement. Curr Opin Allergy Clin Immunol 2007;7:37-42.

77. Hull JH, Backer V, Gibson PG, Fowler SJ. Laryngeal dysfunction: assessment and management for the clinician. Am J Respir Crit Care Med 2016;194:1062-72.

78. Blitzer A, Brin MF. Laryngeal dystonia: a series with botulinum toxin therapy. Ann Otol Rhinol Laryngol 1991;100:85-9.

79. Gibson PG, Ryan NM. Cough pharmacotherapy: current and future status. Expert Opin Pharmacother 2011;12:1745-55.

80. Bolser DC. Mechanisms of action of central and peripheral antitussive drugs. Pulm Pharmacol 1996;9:357-64.

81. Balsamo R, Lanata L, Egan CG. Mucoactive drugs. Eur Respir Rev 2010;19:127-33.

82. Rogers DF. Mucoactive agents for airway mucus hypersecretory diseases. Respir Care 2007;52:1176-93. 